\title{
Criação de um modelo de indicador de salubridade ambiental (ISA) adaptado ao contexto de municípios de pequeno porte (ISA/MPP)
}

O saneamento ambiental não deve ser entendido meramente como prestação de serviços de abastecimento de água potável, coleta e tratamento de esgoto, manejo de águas pluviais e manejo de resíduos sólidos. No Brasil, a Política Nacional de Saneamento Básico - PNSB, que regulamenta normas sobre o exercício da regulação, planejamento e gestão do setor, foi instituída por meio da Lei no 11.445/07. O Plano Nacional de Saneamento Básico - PLANSAB, publicado em 2013, prevê o monitoramento de indicadores sobre a execução e gestão dos serviços de saneamento. Acerca do monitoramento, destaca-se como ferramenta de avaliação o Indicador de Salubridade Ambiental - (ISA), desenvolvido pela Câmara Técnica de Planejamento do Conselho Estadual de Saneamento no Estado de São Paulo (CONESAN), em 1999. O ISA permite verificar as condições de salubridade em âmbito municipal, identificar e avaliar as condições de saneamento de cada município de maneira uniforme. Diante da necessidade de conhecer melhor a realidade dos municípios de pequeno porte quanto aos serviços de saneamento e a salubridade ambiental, esse artigo visou discutir e propor um modelo de ISA que possa servir de base para a elaboração de Planos Municipais de Saneamento Básico - PMSBs e políticas públicas específicas voltadas a estes municípios A metodologia aplicada envolveu revisão bibliográfica; coleta de dados; adaptação do ISA CONESAN para criar o modelo do Indicador de Salubridade Ambiental para municípios de pequeno porte - ISA/MPP, estruturação dos indicadores e planilhas de cálculo; e teste de aplicação do modelo criado em municípios paraibanos. O ISA/MPP mostrou-se viável tanto ao contexto dos municípios de pequeno porte como ao dos municípios de grande porte. As adaptações propostas conseguiram atender a necessidade de incluir dados acessíveis e indicadores que considerassem peculiaridades dos municípios de pequeno porte.

\section{Creation of a model of environmental health INDICATOR (ISA) adapted to the context of small municipalities (ISA/MPP)}

\begin{abstract}
Environmental sanitation should not be provided only as provision of drinking water supply, sewage collection and treatment, rainwater management and waste management. In Brazil, a National Basic Sanitation Policy - PNSB, which regulates the rules on the exercise of inspection, planning and management of the sector, was instituted through Law no 11.445/07. The National Basic Sanitation Plan - PLANSAB, published in 2013, estimates the monitoring of indicators on the execution and management of sanitation services. Monitoring fence, displayed as an assessment tool or Environmental Health Indicator - (ISA), developed by the Technical Planning Chamber of the State Sanitation Council of the State of São Paulo (CONESAN), in 1999. ISA allows you to check health conditions at the municipal level, uniformly identify and evaluate the sanitation conditions of each municipality. Given the need to better understand the reality of small-sized municipalities on sanitation and environmental services, this article shows how to discuss and propose an ISA model that can use the basis for the preparation of municipal basic sanitation plans - PMSBs and specific public policies aimed at these municipalities The applied methodology involves bibliographic review; data collect; adaptation of ISA CONESAN to create the Environmental Health Indicator model for small municipalities - ISA/MPP, structuring indicators and calculation plans; and application test of the model created in the municipalities of Paraiba. ISA/MPP proved to be viable in the context of both small and large municipalities. How the proposed adaptations were able to meet the need to include available data and indicators that consider peculiarities of small municipalities.
\end{abstract}

Keywords: Environmental Sanitation; Environmental Health Indicator; Small Municipalities.

Topic: Desenvolvimento, Sustentabilidade e Meio Ambiente

Reviewed anonymously in the process of blind peer.
Received: 05/02/2020

Approved: 01/03/2020
Jhersyka Barros Barreto (iD)

Universidade Federal de Campina Grande, Brasil

http://lattes.cnpq.br/8758104489423780

http://orcid.org/0000-0003-2008-6342

ihersykab.barretto@gmail.com

Patrícia Hermínio Cunha Feitosa (iD

Universidade Federal de Campina Grande, Brasil

http://lattes.cnpq.br/8276706034302451

http://orcid.org/0000-0001-6937-0817

phcfeitosa@outlook.com

Kainara Lira dos Anjos (iD

Universidade Federal de Campina Grande, Brasil

http://lattes.cnpq.br/2288961603074693

http://orcid.org/0000-0001-9327-5334

kainaraanjos@gmail.com
Ruan Otávio Teixeira (iD

Universidade Federal de Campina Grande, Brasil

http://lattes.cnpq.br/9727018668756774

http://orcid.org/0000-0002-0156-6394

ruanotavio@gmail.com
Referencing this:

BARRETO, J. B.; FEITOSA, P. H. C.; ANJOS, K. L.; TEIXEIRA, R. O.. Criação de um modelo de indicador de salubridade ambiental (ISA) adaptado ao contexto de municípios de pequeno porte (ISA/MPP). Revista Ibero Americana de Ciências Ambientais, v.11, n.2, p.278-295, 2020. DOI: http://doi.org/10.6008/CBPC2179-6858.2020.002.0028 


\section{INTRODUÇÃO}

O saneamento ambiental não deve ser entendido meramente como prestação de serviços de abastecimento de água potável, coleta e tratamento de esgoto, manejo de águas pluviais e manejo de resíduos sólidos. O acesso à água e ao saneamento é considerado como direito humano fundamental pela Organização das Nações Unidas (ONU) desde 2010 (ZANCUL, 2015). Além disso, o saneamento está atrelado à saúde pública, pois as condições de insalubridade ambiental favorecem a ocorrência de endemias e epidemias de determinadas doenças.

No Brasil, a Política Nacional de Saneamento Básico - PNSB, que regulamenta normas sobre o exercício da regulação, planejamento e gestão do setor, é recente, tendo sido instituída pela Lei no 11.445 de 5 de janeiro de 2007. Já o Plano Nacional de Saneamento Básico - PLANSAB foi elaborado posteriormente e publicado em 2013. O PLANSAB apresenta como princípios fundamentais da PNSB: a universalização, a equidade, a intersetorialidade, a sustentabilidade, a participação e o controle social. Há a obrigatoriedade da elaboração do Plano de Saneamento Básico por parte dos Estados e municípios, de forma que os planos de investimentos e os projetos sejam compatíveis com o que foi estabelecido pelo Plano.

Outro aspecto que deve ser considerado, segundo o PLANSAB, é a prática intersetorial nos serviços de saneamento básico, de forma que possa vincular análises, planos, programas, decisões e ações para a melhoria dos serviços. Esta prática é importante pois deve-se estimular ações de saneamento articuladas e integradas com os outros programas e políticas públicas de áreas relacionadas, como, por exemplo, o desenvolvimento de interrelações desses serviços com: a gestão ambiental; a gestão dos recursos hídricos; o planejamento do uso e ocupação do solo; ações de controle de doenças de veiculação hídrica, entre outros (MINISTÉRIO DAS CIDADES, 2013).

Além disso, o PLANSAB prevê o monitoramento de indicadores sobre a execução e gestão dos serviços de saneamento (IBGE, 2018). Destaca-se como ferramenta de avaliação o Indicador de Salubridade Ambiental - ISA, desenvolvido pela CONESAN, em 1999, que permite verificar as condições de salubridade em âmbito municipal, identificar e avaliar as condições de saneamento de cada município de maneira uniforme. O ISA é um índice (ou indicador composto) formado por indicadores selecionados da área de saneamento básico: abastecimento de água; esgotamento sanitário; resíduos sólidos; drenagem urbana; indicadores de saúde pública; e socioeconômicos.

Ao longo dos últimos 20 anos tem sido utilizado como referência para a elaboração de outras políticas públicas em distintas localidades e em outros estudos e trabalhos acadêmicos, o que reforça a confiabilidade, utilidade, validade, adaptabilidade e relevância desse indicador. Nesse sentido, diante da necessidade de conhecer melhor a realidade dos municípios de pequeno porte, esse artigo visa discutir e propor um modelo de ISA que possa servir de base para a elaboração de PMSBs e políticas públicas específicas voltadas a estes municípios. Esse modelo foi nomeado como 'ISA/MPP', criado a partir da adaptação do ISA CONESAN, com a inclusão de indicadores de primeira e de segunda ordem que agreguem peculiaridades do saneamento básico desses municípios. 


\section{REVISÃO TEÓRICA}

Os indicadores e índices são considerados por Carvalho (2008) medidas parciais e aproximativas de sustentabilidade, úteis tanto para estudo e pesquisa, como para o planejamento, implementação de políticas e tomadas de decisões relacionadas ao desenvolvimento sustentável nas esferas públicas e privadas. Ele afirma que "o indicador é a estatística que melhor avalia as condições e tendências relativas a um determinado tema" (CARVALHO, 2008). Segundo Silva (2006), a Organização de Cooperação e Desenvolvimento Econômico - OCDE define o indicador como sendo um parâmetro, ou um valor derivado de um parâmetro, que permite descrever e analisar um estado de fenômeno do meio ambiente ou de uma zona geográfica.

Sendo assim, o ISA pode ser considerado um parâmetro que permite avaliar a situação de salubridade ambiental, por meio de indicadores de primeira e segunda ordem, também denominados de subindicadores, referentes às condições sanitárias, aos aspectos ambientais e aos aspectos socioeconômicos de cada município. De acordo com Almeida (1999), esse Indicador trata-se de um modelo desenvolvido com o objetivo específico de verificar as condições de salubridade em âmbito municipal, para identificar e avaliar, de maneira uniforme, as condições de saneamento de cada município.

O ISA é calculado pela média ponderada de indicadores específicos e relacionados, direta ou indiretamente, com a salubridade ambiental (ALMEIDA, 1999). O cálculo do ISA desenvolvido pela CONESAN em São Paulo (ISA/SP), foi realizado por meio da aplicação da seguinte fórmula:

\section{Equação 1. ISA = 0,25 IAB + 0,25 IES + 0,25 IRS + 0,10 ICV + 0,10 IRH + 0,05 ISE.}

A 'Equação 1' tem sido a base para a adaptação e aplicação do ISA em diversos outros contextos e localidades. Os pesos referentes ao Indicador de Abastecimento de Água (IAB); Indicador de Esgotamento Sanitário (IES); Indicador de Resíduos Sólidos (IRS) correspondem a 25\% cada um, destacando a relevância desses indicadores para o saneamento e salubridade ambiental. O Indicador de Controle de Vetores (ICV) e o Indicador de Riscos de Recursos Hídricos (IRH), possuem o peso de $10 \%$ cada, e para o Indicador Socioeconômico (ISE) foi atribuído o peso de 5 \% (Tabela 1).

Os critérios de cálculo do ISA foram estabelecidos pelo Manual Básico do ISA, onde cada indicador de primeira ordem é calculado por meio da média ponderada dos seus indicadores de segunda ordem (ALMEIDA, 1999). Os níveis de salubridade ambiental variam de acordo com o resultado obtido através da aplicação do ISA, sendo assim, o município pode ser classificado em: Insalubre, com Baixa Salubridade, com Média Salubridade e Salubre (Tabela 1).

Embora o ISA tenha sido desenvolvido para a avaliação das condições de salubridade ambiental dos municípios paulistas, a sua metodologia de aplicação e possibilidade de adaptação permite sua replicabilidade. Por essa razão, o ISA, tem sido utilizado como ferramenta para avaliação em diversos estudos acadêmicos e em Planos Municipais de Saneamento Básico (PMSBs) para auxiliar na tomada de decisões por parte do poder público em relação as áreas prioritárias para investimento dos recursos financeiros e desenvolvimento de políticas públicas específicas, considerando aspectos reais para o planejamento de 
curto, médio e longo prazo.

Tabela 1: Base para o cálculo do ISA e nível de salubridade proposto pela CONESAN.

\begin{tabular}{|c|c|c|c|c|c|}
\hline \multicolumn{6}{|c|}{ ISA = 0,25 IAB + 0,25 IES + 0,25 IRS + 0,10 ICV + 0,10 IRH + 0,05 ISE } \\
\hline $\begin{array}{ll}\text { Indicador } & \text { de } \\
\text { Abastecimento } & \text { de } \\
\text { Água (IAB) } & \\
\end{array}$ & $\begin{array}{ll}\text { Indicador } & \text { de } \\
\text { Esgotamento } & \\
\text { Sanitário (IES) } & \\
\end{array}$ & $\begin{array}{l}\text { Indicador de } \\
\text { Resíduos } \\
\text { Sólidos (IRS) } \\
\end{array}$ & $\begin{array}{ll}\text { Indicador } & \text { de } \\
\text { Controle } & \text { de } \\
\text { Vetores (ICV) } & \\
\end{array}$ & $\begin{array}{l}\text { Indicador de } \\
\text { Recursos } \\
\text { Hídricos (IRH) }\end{array}$ & $\begin{array}{l}\text { Indicador } \\
\text { Socioeconômico } \\
\text { (ISE) }\end{array}$ \\
\hline \multicolumn{6}{|c|}{ SALUBRIDADE AMBIENTAL DE ACORDO COM O RESULTADO DO ISA } \\
\hline Insalubre & \multicolumn{2}{|c|}{ Baixa Salubridade } & \multicolumn{2}{|l|}{ Média Salubridade } & Salubre \\
\hline $0-0,25$ & \multicolumn{2}{|l|}{$0,26-0,50$} & \multicolumn{2}{|l|}{$0,51-0,75$} & $0,76-1,00$ \\
\hline
\end{tabular}

Fonte: Adaptado de Almeida (1999).

A primeira adaptação que deve ser proposta na construção de um modelo ISA é referente aos indicadores e os respectivos pesos atribuídos. Vários estudos e PMSBs que utilizaram o ISA adotaram pesos distintos, além de adotarem novos indicadores de primeira e segunda ordem e/ou descartarem alguns. Cabe aos autores dos estudos e PMSBs definirem os indicadores que irão compor o seu ISA, com base no modelo desenvolvido pela CONESAN e/ou outros modelos criados a partir dele, e considerando as peculiaridades da pesquisa.

Alguns estudos e PMSBs adotaram o mesmo peso proposto pela CONESAN (ALMEIDA, 1999), como é o caso dos estudos elaborados por Souza (2010), Cunha (2012), Cabral (2015) e os PMSBs dos municípios de Apiaí/SP (2010) e Olímpia/SP (2010). Outros autores adotaram pesos com base na revisão bibliográfica, seguindo os indicadores e pesos adotados por determinados autores em estudos semelhantes. No entanto, alguns desses autores redistribuíram os valores do peso de acordo com a retirada e/ou adoção de novos indicadores, Teixeira (2017) classificou esse método de escolha dos pesos como 'arbitrário'.

O Método Delphi foi aplicado por Silva (2006), por Costa (2010) e por Teixeira (2017). Teixeira (2017) explica que esse método consiste na consulta de um grupo de especialistas com intuito de obter informações a respeito de um determinado assunto, por meio de um questionário que é repassado ao grupo repetidas vezes até que se alcance um nível de consenso, representando uma opinião consolidada desses especialistas. De certa forma, através da aplicação desta técnica, a distribuição dos pesos pode ser transferida ao julgamento coletivo de profissionais da área, o que apresenta uma melhor justificativa para a definição dos pesos de cada indicador em relação ao método arbitrário, que considera apenas a opinião do próprio autor.

Diante da diversidade de métodos e de pesos propostos, optou-se por analisar, inicialmente, os pesos e quais os indicadores foram adotados e/ou descartados, além dos novos indicadores propostos nos estudos e PMSBs que trabalharam com o ISA, nos últimos 20 anos (1999-2019). Dentre os 48 trabalhos considerados, 62,5\% são estudos acadêmicos a nível de mestrado e doutorado, e 37,5\% são PMSBs. Dos trabalhos de pósgraduação apenas 7\% são Teses de Doutorado e 93\% são Dissertações de Mestrado, o que representa uma intensa produção de estudos e aplicações do ISA a nível de mestrado a partir de sua criação em 1999 até a atualidade (Tabelas 2).

Quanto às variações do ISA, tem-se que apenas o PMSB de São Pedro do Iguaçu (2017) alterou completamente a estrutura do indicador em relação ao original, propondo como indicadores de primeira ordem: o Índice Sanitário, Índice Epidemiológico, Índice Ambiental e Índice Socioeconômico. Por essa razão, 
o ISA em questão foi descartado em relação a análise dos pesos atribuídos, já que a estrutura difere completamente dos outros estudos e PMSB, permanecendo, portanto, 47 modelos a serem analisados.

Tabela 2: Pesos de Indicadores de Primeira Ordem em ISA de Estudos Acadêmicos e PMSBs.

\begin{tabular}{|c|c|c|c|c|c|c|c|c|c|}
\hline \multirow{2}{*}{ Autor (ano) } & \multirow{2}{*}{$\begin{array}{l}\text { Estudos } \\
\text { Acadêmicos }\end{array}$} & \multicolumn{8}{|c|}{ Peso dos indicadores de primeira ordem do ISA } \\
\hline & & IAB & IES & IRS & ICV & IRH & ISE & IDU & ICM \\
\hline São Paulo (Conesan) & Conesan & 0,25 & 0,25 & 0,25 & 0,10 & 0,10 & 0,05 & - & - \\
\hline Almeida (1999) & Tese & 0,0714 & 0,0714 & 0,0714 & - & - & - & 0,0714 & - \\
\hline Dias (2003) & Dissertação & 0,20 & 0,20 & 0,15 & - & - & 0,10 & 0,10 & 0,15 \\
\hline Oliveira (2003) & Dissertação & 0,30 & 0,20 & 0,20 & 0,10 & - & 0,10 & - & - \\
\hline Neri (2005) & Dissertação & 0,25 & 0,25 & 0,10 & - & - & 0,10 & - & 0,15 \\
\hline Batista (2005) & Dissertação & 0,25 & 0,20 & 0,20 & 0,10 & 0,10 & 0,05 & 0,10 & - \\
\hline Azevedo (2006) & Tese & 0,0714 & 0,0714 & 0,0714 & - & - & - & 0,0714 & - \\
\hline Bahia (2006) & Dissertação & 0,30 & 0,20 & 0,20 & 0,10 & - & 0,10 & - & - \\
\hline Silva (2006) & Dissertação & 0,20 & 0,20 & 0,15 & 0,10 & 0,10 & 0,05 & 0,10 & 0,10 \\
\hline Menezes (2007) & Dissertação & 0,20 & 0,20 & 0,15 & - & - & 0,10 & 0,10 & 0,15 \\
\hline Santos (2008) & Dissertação & 0,25 & 0,25 & - & - & 0,15 & 0,10 & 0,25 & - \\
\hline Rocha (2008) & Dissertação & 0,30 & 0,20 & 0,20 & 0,10 & - & 0,10 & - & - \\
\hline Silva (2009) & Dissertação & 0,20 & 0,20 & 0,15 & - & - & 0,10 & 0,10 & 0,15 \\
\hline Costa (2010) & Dissertação & 0,15 & 0,20 & 0,10 & 0,15 & - & 0,10 & - & 0,15 \\
\hline Aravéchia Junior (2010) & Dissertação & 0,30 & 0,20 & 0,20 & 0,10 & 0,10 & 0,10 & - & - \\
\hline Buckley (2010) & Dissertação & 0,15 & 0,15 & 0,10 & 0,10 & - & - & - & 0,15 \\
\hline Souza (2010) & Dissertação & 0,25 & 0,25 & 0,25 & 0,10 & 0,10 & 0,05 & - & - \\
\hline Cunha (2012) & Dissertação & 0,25 & 0,25 & 0,25 & 0,10 & 0,10 & 0,05 & - & - \\
\hline Santos (2012) & Dissertação & 0,40 & 0,30 & 0,10 & - & - & - & 0,20 & - \\
\hline Gama (2013) & Dissertação & 0,30 & 0,30 & 0,20 & - & - & - & 0,20 & - \\
\hline Viana (2013) & Dissertação & 0,25 & 0,35 & 0,25 & 0,15 & - & - & - & - \\
\hline Pedrosa (2014) & Dissertação & 0,20 & 0,20 & 0,15 & 0,10 & - & 0,10 & 0,10 & 0,15 \\
\hline Lima (2014) & Dissertação & 0,275 & 0,275 & 0,275 & 0,125 & - & 0,05 & - & - \\
\hline Cabral (2015) & Dissertação & 0,25 & 0,25 & 0,25 & 0,10 & 0,10 & 0,05 & - & - \\
\hline Barbosa Segundo (2015) & Dissertação & 0,25 & 0,20 & 0,20 & 0,10 & 0,10 & 0,05 & 0,10 & - \\
\hline Rocha (2016) & Dissertação & 0,10 & 0,20 & 0,20 & - & - & 0,30 & 0,20 & \\
\hline Teixeira (2017) & Dissertação & 0,203 & 0,207 & 0,168 & 0,105 & 0,107 & 0,113 & 0,095 & - \\
\hline Santos (2017) & Dissertação & 0,20 & 0,20 & 0,20 & 0,20 & - & - & 0,20 & - \\
\hline Duarte (2018) & Dissertação & 0,25 & 0,25 & 0,25 & 0,10 & - & 0,15 & - & - \\
\hline Colina (2018) & Dissertação & 0,30 & 0,30 & 0,15 & 0,10 & - & 0,15 & - & - \\
\hline Maccarini (2019) & Dissertação & 0,25 & 0,20 & 0,20 & 0,10 & 0,10 & 0,50 & 0,10 & - \\
\hline Município (ano) & PMSBs & IAB & IES & IRS & ICV & IRH & ISE & IDU & ICM \\
\hline Apiaí/SP (2010) & PMSB & 0,25 & 0,25 & 0,25 & 0,10 & 0,10 & 0,05 & - & - \\
\hline Olímpia/SP (2010) & PMSB & 0,25 & 0,25 & 0,25 & 0,10 & 0,10 & 0,05 & - & - \\
\hline Parnamirim/RN (2010) & PMSB & 0,20 & 0,25 & 0,25 & - & - & - & 0,30 & - \\
\hline Videira/SC (2010) & PMSB & 0,35 & 0,25 & 0,15 & - & - & 0,15 & 0,10 & - \\
\hline Doutor Pedrinho/SC (2011) & PMSB & 0,25 & 0,25 & 0,25 & - & - & & 0,25 & - \\
\hline Florianópolis/SC (2011) & PMSB & 0,10 & 0,50 & 0,20 & - & - & - & 0,20 & - \\
\hline Forquilhinha/SC (2011) & PMSB & 0,20 & 0,20 & 0,20 & 0,10 & 0,10 & - & 0,20 & - \\
\hline Rio do Sul/SC (2011) & PMSB & 0,25 & 0,25 & 0,20 & - & - & 0,10 & 0,20 & - \\
\hline Igatu/CE (2011) & PMSB & 0,35 & 0,25 & 0,25 & - & - & - & 0,15 & - \\
\hline Salete/SC (2011) & PMSB & 1 & 1 & 1 & - & - & - & 1 & - \\
\hline São José/SC (2013) & PMSB & 0,15 & 0,35 & 0,20 & 0,10 & - & - & 0,20 & - \\
\hline Chapada/RS (2013) & PMSB & 0,25 & 0,25 & 0,25 & - & - & - & 0,25 & - \\
\hline Barbacena/MG (2014) & PMSB & 0,25 & 0,25 & 0,25 & - & - & - & 0,25 & - \\
\hline Belo Horizonte/MG (2014) & PMSB & 0,05 & 0,35 & 0,20 & - & - & - & 0,40 & - \\
\hline Santa Cruz/RN (2015) & PMSB & 0,35 & 0,25 & 0,25 & - & - & - & 0,20 & - \\
\hline Rebouças Urbano/PR (2016) & PMSB & 0,20 & 0,30 & 0,20 & - & - & - & 0,30 & - \\
\hline Rebouças Rural/PR (2016) & PMSB & 0,25 & 0,40 & 0,35 & - & - & - & - & - \\
\hline $\begin{array}{l}\text { São Pedro do Iguaçu/PR } \\
(2017)\end{array}$ & PMSB & $\begin{array}{l}0,60 \\
\text { ISan }\end{array}$ & $\begin{array}{l}0,10 \\
\text { IEp }\end{array}$ & $\begin{array}{l}0,10 \\
\mathrm{IAm}\end{array}$ & $\begin{array}{l}0,20 \\
\text { ISe }\end{array}$ & - & - & - & - \\
\hline
\end{tabular}

Fonte: Adaptado e atualizado de Teixeira et al. (2018).

Os demais trabalhos utilizaram o ISA CONESAN como base, propondo algumas alterações referentes a retirada e acréscimo de indicadores. Destes, apenas $11 \%$ mantiveram a estrutura de indicadores e pesos 
estabelecidos originalmente. Em relação aos indicadores de primeira ordem, todos os estudos mantiveram o Indicador de Abastecimento de Água (IAB) e o Indicador de Esgotamento Sanitário (IES), o que demonstra a maior relevância desses indicadores comparados aos demais (Tabelas 2).

O Indicador de Resíduos Sólidos (IRS) foi mantido em 98\% dos estudos. O Indicador de Controle de Vetores (ICV) foi retirado em muitos estudos, sendo mantido por $51 \%$ dos trabalhos, enquanto o Indicador de Recursos Hídricos (IRH) foi mantido em apenas 28\%. Já o Indicador Socioeconômico foi mantido em $57 \%$ dos trabalhos considerados. Quanto ao acréscimo de indicadores, observou-se que o Indicador de Drenagem Urbana (IDU), proposto inicialmente por Almeida (1999), foi adotado por 64\% dos estudos. E o Indicador de Condições de Moradia (ICM), foi adotado por $17 \%$ dos trabalhos.

\section{METODOLOGIA}

A metodologia aplicada para a adaptação do Indicador de Salubridade Ambiental (ISA) ao contexto dos municípios de pequeno porte (ISA/MPP) se dividiu nas seguintes etapas metodológicas: i) Caracterização do Universo Empírico do Estudo; ii) Estudo de Caso; iii) Adaptações do ISA; iv) Aplicação do ISA/MPP; e v) Resultados do ISA/MPP. Na Figura 1, o fluxograma apresenta o passo a passo realizado em cada etapa da criação do modelo ISA/MPP.

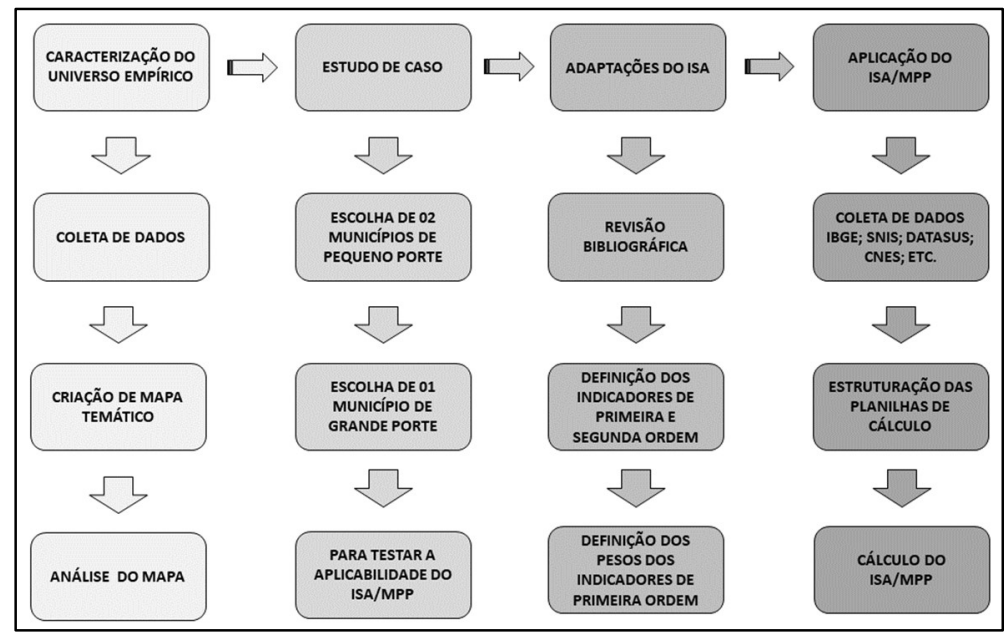

Figura 1: Fluxograma das etapas metodológicas.

\section{Caracterização do Universo Empírico do Estudo}

Para a Caracterização do Universo Empírico de Estudo foi criado um mapa populacional da Paraíba, através do software Quantum GIS (QGIS), versão 3.2, com as delimitações das Regiões Geográficas Intermediárias e Imediatas definidas pelo IBGE (2017). A partir da análise desse mapa, foi possível observar que: do total de 223 municípios da Paraíba, 61\% possuem menos de 10 mil habitantes, 34\% possuem população entre 10 e 50 mil habitantes e aproximadamente 5\% possuem uma população superior a 50 mil habitantes (Figura 2).

O fato de $95 \%$ dos municípios paraibanos estarem dentro da faixa populacional de até 50 mil habitantes e a maioria desses municípios (61\%) possuírem uma população de até 10 mil habitantes, surgiu o interesse de desenvolver o ISA/MPP para ser aplicado em municípios de pequeno porte, o que não inviabiliza 
a possibilidade de aplicar esse modelo a municípios que estejam dentro de outras faixas populacionais.

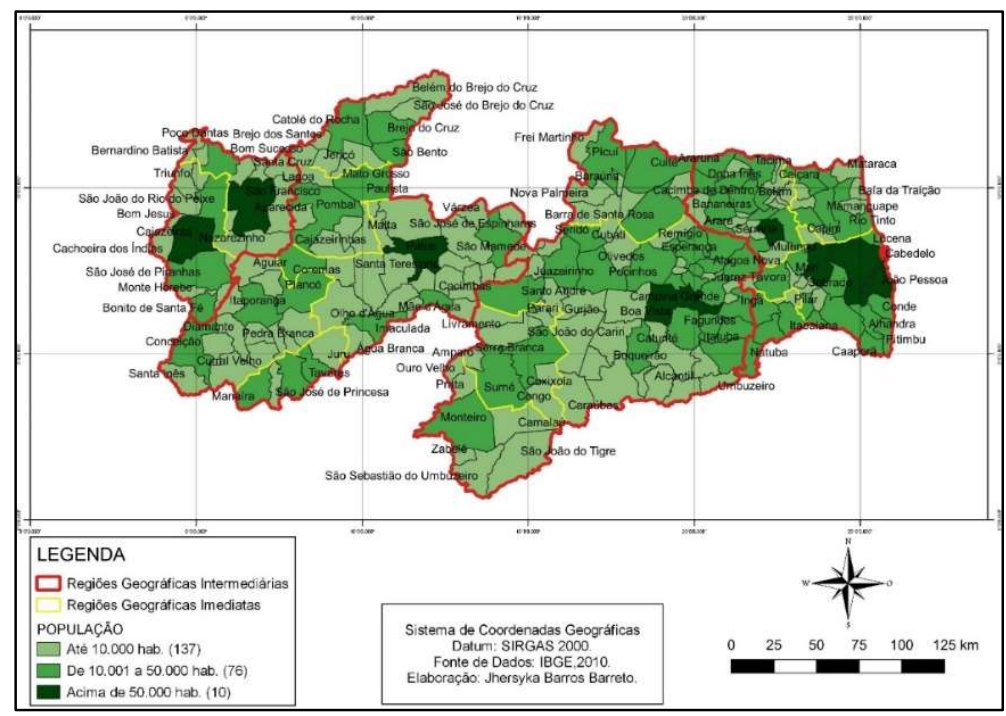

Figura 2: Mapa populacional dos municípios da Paraíba.

\section{Estudo de Caso}

Os municípios escolhidos para a aplicação do ISA/MPP foram: Cuité de Mamanguape e Marcação, além de João Pessoa, que é a capital da Paraíba e da Região Geográfica Intermediária onde esses dois municípios de pequeno porte estão localizados (Tabela 3).

Tabela 3: Dados populacionais dos municípios selecionados para a aplicação do ISA/MPP.

\begin{tabular}{|l|l|l|l|l|l|l|}
\hline $\begin{array}{l}\text { Região } \\
\text { Intermediária } \\
\text { (total munic.) }\end{array}$ & Município & População Urbana & População Rural & População Total & $\begin{array}{l}\text { Domicílios } \\
\text { Totais }\end{array}$ & $\begin{array}{l}\text { Prestador } \\
\text { Serviços* }\end{array}$ \\
\hline \multirow{2}{*}{$\begin{array}{l}\text { João Pessoa } \\
\text { (63) }\end{array}$} & João Pessoa & 720785 & 2730 & 723515 & 213256 & CAGEPA \\
\cline { 2 - 8 } & $\begin{array}{l}\text { Cuité } \\
\text { Mamanguape }\end{array}$ & $\mathbf{2 0 6 9}$ & 4133 & 6202 & 1729 & CAGEPA \\
\cline { 2 - 8 } & Marcação & 2849 & 4760 & 7609 & 2040 & P.M. \\
\hline
\end{tabular}

Legenda: *Prestadores de Serviço: CAGEPA = Companhia de Água e Esgoto da Paraíba; P.M. = Prefeitura Municipal. Fonte: Elaborada com base em dados do Censo IBGE (2010).

Após a definição dos municípios, foi criado um banco de dados sobre os serviços de abastecimento de água, esgotamento sanitário, resíduos sólidos, drenagem urbana, saúde pública e aspectos socioeconômicos com as informações necessárias para compor os indicadores de primeira e segunda ordem do ISA/MPP.

\section{RESULTADOS E DISCUSSÃO}

\section{Adaptação do Indicador de Salubridade Ambiental (ISA)}

A proposta de adaptação do ISA em um indicador que atenda peculiaridades dos municípios de pequeno porte partiu da necessidade de encontrar e criar indicadores de primeira e segunda ordem compostos por dados acessíveis, de fácil aplicação e que pudessem ser calculados de forma simplificada. Foram priorizados os dados disponibilizados em bancos de dados nacionais e públicos, como o do Instituto Brasileiro de Geografia e Estatística (IBGE); Sistema Nacional de Informações sobre Saneamento (SNIS); 
DATASUS etc., que possibilitem acompanhar e comparar os resultados do ISA/MPP a partir de novos dados disponibilizados em um intervalo de tempo.

No ISA/MPP se optou por manter o IAB, o IES e o IRS. O IRH foi retirado e teve seus indicadores de segunda ordem considerados relevantes agregados ao IAB. Por essa razão, o peso que seria atribuído ao IRH também foi somado ao peso do IAB, na etapa de definição dos pesos do ISA/MPP. O IDU foi adotado devido a sua relevância, por ser um dos serviços que compõe o saneamento básico, que pode ser notada pela quantidade de trabalhos que adotaram esse indicador. Outro ponto positivo é a possibilidade de gerar informações de drenagem urbana a partir do uso de geoprocessamento e a obtenção de dados em sistemas de informações disponíveis. O ICV foi substituído pelo Indicador de Saúde Pública (ISP), mantendo-se o mesmo peso atribuído ao ICV. O ISE também foi substituído pelo Índice de Desenvolvimento Humano (IDH), já que esse índice é um método comparativo que agrega indicadores de longevidade, renda e educação, já estando disponível para todos os municípios.

Na etapa de definição dos pesos do ISA/MPP (Tabela 4), foram considerados o total de 48 trabalhos, sendo o ISA CONESAN e os outros 47 estudos citados na revisão teórica. O método escolhido para a definição do peso dos indicadores foi o cálculo da média dos pesos adotados pelos trabalhos considerados nesse estudo. Dessa forma, foram realizadas as adaptações necessárias já citadas, referentes ao peso do IRH que foi somado ao peso do IAB, além dos indicadores que foram substituídos, mas mantiveram o mesmo peso do indicador antigo (o peso do ISP corresponde ao peso do ICV; e o peso do IDH corresponde ao peso do ISE), com o acréscimo do IDU.

Tabela 4: Definição de Pesos de Indicadores de Primeira Ordem do ISA/MPP.

\begin{tabular}{|l|l|l|l|l|l|l|l|}
\hline ISA & IAB & IES & IRS & - & ICV & ISE & IRH \\
\hline CONESAN & 0,25 & 0,25 & 0,25 & - & 0,10 & 0,05 & 0,10 \\
\hline ISA & IAB & IES & IRS & IDU & ICV & ISE & IRH \\
\hline Média & $\mathbf{0 , 2 5}$ & $\mathbf{0 , 2 6}$ & $\mathbf{0 , 2 1}$ & 0,13 & $\mathbf{0 , 0 6}$ & 0,06 & 0,03 \\
\hline ISA & IAB & IES & IRS & IDU & ISP & IDH & \\
\hline MPP & $\mathbf{0 , 2 8}$ & $\mathbf{0 , 2 6}$ & $\mathbf{0 , 2 1}$ & $\mathbf{0 , 1 3}$ & $\mathbf{0 , 0 6}$ & $\mathbf{0 , 0 6}$ & \\
\hline
\end{tabular}

Dessa forma, a equação para o cálculo do ISA/MPP é composta pelos seguintes indicadores e respectivos pesos:

Equação (2). ISA/MPP = (0,28 IAB + 0,26 IES + 0,21 IRS + 0,13 IDU + 0,06 ISP + 0,06 IDH $) / 100$

Optou-se por adotar, predominantemente, dados de fácil acesso, como os do Censo do IBGE, que permitem tanto a replicabilidade em outros estados e municípios do país, como a possibilidade de acompanhar e comparar os indicadores ao longo dos anos. Além disso, outros bancos de dados complementares (SNIS, DATASUS, ATLAS 2013, etc.) também foram considerados como fonte de coleta. Em relação a composição dos indicadores, cálculo, critérios de pontuação e o objetivo, serão abordados individualmente em cada indicador de primeira ordem para facilitar a compreensão das decisões metodológicas adotadas e propostas.

\section{Indicador de Abastecimento de Água (IAB)}

O Indicador de Abastecimento de Água apresenta o maior peso no ISA/MPP, que é de 0,28 (Tabela 
4), é sendo calculado através da equação: IAB=(Ica+lqa+ldm+lsa+lof)/5. No ISA CONESAN, o IAB tem como indicadores de segunda ordem: i) Cobertura de Abastecimento (Ica), que tem como objetivo quantificar o percentual de domicílios atendidos pela rede geral; ii) Qualidade de Água Distribuída (Iqd), que visa monitorar a qualidade da água oferecida; e iii) Saturação do Sistema Produtor (Isa), que visa comparar a situação da oferta e a demanda de água no município.

Quadro 1: Método de aplicação do Indicador de Abastecimento de Água (IAB)

\begin{tabular}{|c|c|c|c|c|c|}
\hline 을 & Indicador & $\begin{array}{l}\text { Cálculo/ } \\
\text { Critério }\end{array}$ & Siglas & Pontuação & Objetivo \\
\hline 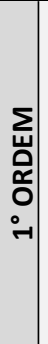 & $\begin{array}{l}\text { Indicador de } \\
\text { Abastecimento de } \\
\text { Água (IAB) }\end{array}$ & $\begin{array}{l}\text { IAB }=(\text { Ica+lqa+I } \\
\mathrm{dm}+\text { Isa+lof }) / 5\end{array}$ & $\begin{array}{l}\text { Ica: Indicador de cobertura de } \\
\text { abastecimento de água; } \\
\text { Iqa: Indicador da qualidade da água; } \\
\text { Idm: Indicador de disponibilidade do } \\
\text { manancial; } \\
\text { Isa: Indicador de situação do } \\
\text { abastecimento; } \\
\text { lof: Indicador de outras fontes de } \\
\text { abastecimento. }\end{array}$ & $\begin{array}{l}\text { Média dos } \\
\text { indicadores de } 2^{\circ} \\
\text { ordem }\end{array}$ & $\begin{array}{l}\text { Quantificar a } \\
\text { pontuação média } \\
\text { dos indicadores de } \\
\text { segunda ordem. }\end{array}$ \\
\hline \multirow{5}{*}{ 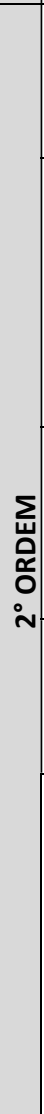 } & $\begin{array}{l}\text { Cobertura de } \\
\text { Abastecimento de } \\
\text { Água (Ica) }\end{array}$ & $\begin{array}{l}\text { Ica= (Drg/Dot) } \\
\text { x } 100 \\
\text { (ISA CONESAN) }\end{array}$ & $\begin{array}{l}\text { Drg: Domicílios atendidos pela rede } \\
\text { geral. } \\
\text { Dot: Domicílios totais }\end{array}$ & $\%$ & $\begin{array}{l}\text { Quantificar o } \\
\text { percentual de } \\
\text { domicílios atendidos } \\
\text { pela rede geral. }\end{array}$ \\
\hline & $\begin{array}{l}\text { Qualidade da Água } \\
\text { Distribuída (Iqa) }\end{array}$ & $\begin{array}{l}\text { lqa }=K x \\
\text { (NAA/NAR) } x \\
100 \\
\text { (ISA CONESAN) }\end{array}$ & $\begin{array}{l}\text { K: no amostras realizadas/no mínimo } \\
\text { de amostras exigidas; } \\
\text { NAA: Quant. de amostra } \\
\text { considerada dentro dos padrões de } \\
\text { potabilidade } \\
\text { NAR: } N^{\circ} \text { de amostras realizadas. }\end{array}$ & $\begin{array}{l}\text { Iqa } \\
100 \%=100 \text { Pontos } \\
95<\text { Iqa }<99 \%=80 \\
85<\text { Iqa }<94 \%=60 \\
70<\text { Iqa }<84 \%=40 \\
50<\text { Iqa }<69 \%=20 \\
\text { Iqa }<49 \%=0\end{array}$ & $\begin{array}{l}\text { Avaliar a qualidade } \\
\text { da água oferecida. }\end{array}$ \\
\hline & $\begin{array}{l}\text { Disponibilidade do } \\
\text { Manancial (Idm) }\end{array}$ & $\begin{array}{l}\text { Dados AESA } \\
(2019)\end{array}$ & - & Volume Atual (\%) & $\begin{array}{l}\text { Quantificar a } \\
\text { disponibilidade do } \\
\text { manancial em } \\
\text { relação ao volume } \\
\text { atual. }\end{array}$ \\
\hline & $\begin{array}{l}\text { Situação do } \\
\text { Abastecimento } \\
\text { (Isa) }\end{array}$ & $\begin{array}{l}\text { Prestador } \\
\text { 1. CAGEPA } \\
\text { 2. Prefeitura } \\
\text { Municipal } \\
\end{array}$ & $\begin{array}{l}\text { CAGEPA: Companhia de Água e } \\
\text { Esgoto da Paraíba. }\end{array}$ & $\begin{array}{l}\text { Paralisado - } 0 \\
\text { Em racionamento - } \\
50 \\
\text { Normal - } 100 \\
\end{array}$ & $\begin{array}{l}\text { Identificar a situação } \\
\text { atual do } \\
\text { abastecimento. }\end{array}$ \\
\hline & $\begin{array}{l}\text { Outras Fontes de } \\
\text { Abastecimento } \\
\text { (lof) }\end{array}$ & $\begin{array}{l}\text { lof }=[(\text { Dot }- \\
\text { Drg }- \text { Dac }) / \\
\text { Dot }] \times 100\end{array}$ & $\begin{array}{l}\text { Dot: Domicílios totais } \\
\text { Drg: Domicílios atendidos pela rede } \\
\text { geral. } \\
\text { Dac: Domicílios abastecidos por } \\
\text { carro-pipa }\end{array}$ & $\begin{array}{l}0=100 \\
1-15=75 \\
16-30=50 \\
31-45=25 \\
\text { Acima de } 45=0\end{array}$ & $\begin{array}{l}\text { Quantificar o } \\
\text { percentual de } \\
\text { domicílios que não } \\
\text { são abastecidos nem } \\
\text { por meio da rede } \\
\text { geral, nem por carro- } \\
\text { pipa, e recorrem a } \\
\text { outras fontes de } \\
\text { abastecimento. }\end{array}$ \\
\hline
\end{tabular}

Fonte: Adaptado de Almeida (1999).

No ISA/MPP foi mantido o Ica, o lqa e se agregou a IAB o Indicador de Disponibilidade do Manancial (Idm), que tem como finalidade quantificar a disponibilidade do manancial em relação ao volume atual, e o de Outras Fontes de Abastecimento (lof), que visa quantificar o percentual de domicílios que não são abastecidos nem por meio da rede geral, nem por carro-pipa, e recorrem a outras fontes de abastecimento. Esses indicadores (Idm e lof) pertenciam ao IRH do ISA e, além desses indicadores, foi acrescentado o Indicador de Situação do Abastecimento (Isa) para identificar qual a situação atual do abastecimento de água no município, se está: normal, em racionamento ou paralisado (Quadro 1). 
O Ica e o Iqa seguem a metodologia de cálculo proposta pelo ISA CONESAN, sendo pontuado de acordo com o critério estabelecido pelo mesmo. Os dados sobre qualidade da água de abastecimento dos municípios em estudo foram obtidos por meio de consulta ao banco de dados do Sistema de Informações sobre o Saneamento (SNIS). No Idm, optou-se por adotar o percentual do volume atual do manancial que abastece o município, o qual percentual corresponde diretamente a pontuação do indicador. As informações foram obtidas por consulta ao banco de dados da Agência Executiva de Gestão das Águas do Estado da Paraíba (AESA).

O Isa, que avalia a situação atual do abastecimento, considera como critério para a pontuação, que: quando o abastecimento da rede geral estiver paralisado, a pontuação será zero, quando estiver em racionamento receberá pontuação média, 50 pontos; e quando estiver normal esse subindicador receberá a pontuação máxima de 100 pontos (Quadro 1). O lof é calculado de acordo com o percentual de domicílios que não são atendidos pela rede geral, nem por meio das políticas públicas de abastecimento de água por carro-pipa, sendo abastecidos por outras fontes como a captação de água da chuva, água bruta retirada diretamente de rios ou reservatórios, poços etc.

Os dados utilizados foram obtidos através da consulta ao último Censo do IBGE (2010), em “Universo - característica da população e do domicílio", e o critério de pontuação atribuído ao lof foi distribuído em cinco faixas de resultados quanto ao percentual de abastecimento por outras fontes, quando esse percentual for de: i) $0 \%$, o lof terá pontuação máxima de 100 pontos; ii) $1-15 \%$, 75 pontos, iii) $16-30 \%$, corresponde a 50 pontos; iv) 31 - 45\%, 25 pontos; v) e quando o percentual de domicílios com outras fontes de abastecimento for acima de 45\%, o lof receberá a pontuação mínima, 0 pontos (Quadro 1).

\section{Indicador de Esgoto Sanitário (IES)}

O Indicador de Esgotamento Sanitário (IES) é calculado através da equação IES= (Ice+ldb+ldi)/3 e o seu peso no ISA/MPP corresponde a $\mathbf{0 , 2 6}$ (Tabela 4). No ISA Conesan tem como subindicadores: i) Cobertura em Coleta de Esgoto e Tanques Sépticos (Ice), que tem como objetivo quantificar os domicílios atendidos por redes de esgoto e/ou tanques sépticos; ii) Esgoto Tratado e Tanques Sépticos (Ite), que visa indicar a redução de carga poluidora; e iii) Saturação do Tratamento (Ise), que visa comparar a oferta e a demanda das instalações de Estações de Tratamento de Esgoto - ETE (ALMEIDA, 1999).

Esses subindicadores foram adaptados à realidade do esgotamento sanitário em municípios de pequeno porte, considerando, principalmente, os dados obtidos sobre a situação do esgotamento sanitário nesses municípios. Observou-se que o banco de dados do SNIS, que deveria ser preenchido pela prefeitura e por prestadores de serviços de saneamento, encontra-se com informações incompletas e em alguns casos não foi respondido pelos municípios, impossibilitando o uso desses dados. Os dados do Censo do IBGE (2010), tem uma maior abrangência e apresenta dados mais completos sobre as condições de esgotamento sanitário dos municípios em escala nacional. 
Quadro 2: Método de aplicação do Indicador de Esgoto Sanitário (IES).

\begin{tabular}{|c|c|c|c|c|c|}
\hline 을 & Indicador & $\begin{array}{l}\text { Cálculo/ } \\
\text { Critério }\end{array}$ & Siglas & Pontuação & Objetivo \\
\hline 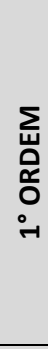 & $\begin{array}{l}\text { Indicador de Esgoto } \\
\text { Sanitário (IES) }\end{array}$ & IES $=(I c e+|d b+| d i) / 3$ & $\begin{array}{l}\text { Ice: Indicador de } \\
\text { cobertura de coleta } \\
\text { de esgoto; } \\
\text { Idb: Indicador de } \\
\text { domicílios com } \\
\text { banheiro; } \\
\text { Idi: Indicador de } \\
\text { domicílios com } \\
\text { descarte inadequado. }\end{array}$ & $\begin{array}{l}\text { Média dos } \\
\text { indicadores } \\
\text { de } 2^{\circ} \text { ordem }\end{array}$ & $\begin{array}{l}\text { Quantificar a pontuação } \\
\text { média dos indicadores } \\
\text { de segunda ordem. }\end{array}$ \\
\hline \multirow[b]{3}{*}{ 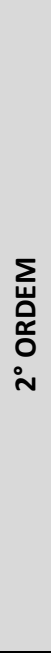 } & $\begin{array}{l}\text { Cobertura em Coleta } \\
\text { de Esgoto (Ice) }\end{array}$ & $\mathrm{Ice}=(\mathrm{Drg} / \mathrm{Dot}) \times 100$ & $\begin{array}{l}\text { Drg: Domicílios } \\
\text { atendidos pela rede } \\
\text { geral. } \\
\text { Dot: Domicílios totais }\end{array}$ & $\%$ & $\begin{array}{l}\text { Quantificar o percentual } \\
\text { de domicílios com coleta } \\
\text { de esgoto por meio da } \\
\text { rede geral. }\end{array}$ \\
\hline & $\begin{array}{l}\text { Domicílios com } \\
\text { Banheiro (Idb) }\end{array}$ & $\mathrm{Idb}=(\mathrm{Dcb} / \mathrm{Dot}) \times 100$ & $\begin{array}{l}\text { Dcb: Domicílios com } \\
\text { banheiro. } \\
\text { Dot: Domicílios totais }\end{array}$ & $\%$ & $\begin{array}{l}\text { Quantificar o percentual } \\
\text { de domicílios com } \\
\text { banheiro. }\end{array}$ \\
\hline & $\begin{array}{l}\text { Domicílios com } \\
\text { Descarte } \\
\text { Inadequado de } \\
\text { Esgoto (Idi) }\end{array}$ & $\begin{array}{l}\text { Idi=[(Dfr+Dda+Ddn)/Dot }] \\
\times 100\end{array}$ & $\begin{array}{l}\text { Dfr: Domicílios com } \\
\text { descarte em fossa } \\
\text { rudimentar; } \\
\text { Dda: Domicílios com } \\
\text { descarte em curso } \\
\text { d'água. } \\
\text { Ddn: Domicílios com } \\
\text { descarte não } \\
\text { especificado; } \\
\text { Dot: Domicílios totais. }\end{array}$ & $\begin{array}{l}0=100 \\
1-15=75 \\
16-30=50 \\
31-45=25 \\
\text { Acima de } 45 \\
=0\end{array}$ & $\begin{array}{l}\text { Quantificar o percentual } \\
\text { de domicílios com } \\
\text { descarte inadequado de } \\
\text { esgoto. }\end{array}$ \\
\hline
\end{tabular}

Fonte: Adaptado de Almeida (1999).

Os indicadores de segunda ordem propostos foram: i) Cobertura de Coleta de Esgoto (Ice), que foi mantido do ISA e corresponde ao percentual de domicílios atendidos pela rede geral; ii) Domicílios com Banheiro (Idb), que visa quantificar o percentual de domicílios com banheiro, com pontuação direta correspondente ao valor obtido pela equação; e iii) Domicílios com Descarte Inadequado de Esgoto (Idi), que visa quantificar o percentual de domicílios não atendidos pela rede geral e que também não possuem fossa séptica, e fazem o descarte do esgoto sanitário em fossa rudimentar, curso d'água etc.

A pontuação do Ice e do Idb correspondem diretamente ao resultado obtido, sendo que são considerados como pontos e não como um percentual. O critério de pontuação atribuído ao Idi foi distribuído em cinco faixas de resultados quanto ao percentual de domicílios com descarte inadequado de esgoto, quando esse percentual for de: i) 0\%, o Idi terá pontuação máxima de 100 pontos; ii) $1-15 \%$, 75 pontos, iii) $16-30 \%$, corresponde a 50 pontos; iv) $31-45 \%$, 25 pontos; v) e quando o resultado do Idi for acima de $45 \%$ corresponde a pontuação mínima, 0 pontos (Quadro 2).

\section{Indicador de Resíduos Sólidos (IRS)}

O Indicador de Resíduos Sólidos (IRS) proposto pelo ISA abrange a Coleta de Resíduos Sólidos (Icr), o Tratamento e a Disposição Final (Iqr) e Indicador de Saturação da Disposição Final (Isr) como indicadores de segunda ordem. A finalidade desse indicador é quantificar o percentual de domicílios atendidos pelo serviço de coleta de resíduos sólidos e indicar a situação do sistema de tratamento e disposição final desses resíduos.

O IRS que compõe o ISA/MPP é calculado através da equação IRS $=(\mathbf{I c r}+\mathbf{l d f + l c p}) / \mathbf{3}$ e possui o peso de 0,21 (Tabela 4). Diante das peculiaridades do manejo e gestão dos resíduos sólidos em municípios de 
pequeno porte, os indicadores de segunda ordem e métodos de cálculo do ISA Conesan apresentaram-se como inviáveis, sendo possível manter apenas o Indicador de Coleta de Resíduos Sólidos (Icr), que foi pontuado diretamente de acordo com o percentual de domicílios atendidos pelos serviços de coleta de resíduos (Quadro 3).

O Indicador de Destinação Final (Idf), foi reformulado de acordo com os dados obtidos, considerando as informações referentes a destinação final dos resíduos realizada por todos os domicílios que não são atendidos pelos serviços de coleta: i) enterram; ii) descartam em curso d'água; iii) descartam em terreno baldio; e iv) queimam os resíduos. O critério de pontuação atribuído ao Idf foi distribuído em cinco faixas de resultados quanto ao percentual de domicílios que não são atendidos pelos serviços municipais de coleta de resíduos, quando esse percentual for de: i) 0\%, o Idf terá pontuação máxima de 100 pontos; ii) 1 - 25\%, 75 pontos, iii) 26 - 50\%, corresponde a 50 pontos; iv) $51-75 \%$, 25 pontos; v) e quando o percentual de domicílios que realizam a própria destinação final dos resíduos for acima de $75 \%$ corresponde a pontuação mínima, 0 pontos (Quadro 3).

Quadro 3: Método de aplicação do Indicador de Resíduos Sólidos (IRS).

\begin{tabular}{|c|c|c|c|c|c|}
\hline F \& & Indicador & Cálculo/ Critério & Siglas & Pontuação & Objetivo \\
\hline 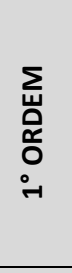 & $\begin{array}{l}\text { Indicador de } \\
\text { Resíduos Sólidos } \\
\text { (IRS) }\end{array}$ & IRS $=(I c r+|d f+| c p) / 3$ & $\begin{array}{l}\text { Icr: Indicador de coleta } \\
\text { de resíduos sólidos; } \\
\text { Idf: Indicador de } \\
\text { destinação final; } \\
\text { Icr: Indicador de } \\
\text { participação em } \\
\text { consórcio de resíduos. }\end{array}$ & $\begin{array}{l}\text { Média dos } \\
\text { indicadores } \\
\text { de } 2^{\circ} \text { ordem }\end{array}$ & $\begin{array}{l}\text { Quantificar a } \\
\text { pontuação média } \\
\text { dos indicadores de } \\
\text { segunda ordem. }\end{array}$ \\
\hline \multirow{3}{*}{ 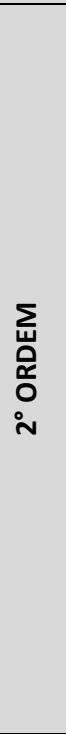 } & $\begin{array}{l}\text { Coleta de } \\
\text { Residuos Sólidos } \\
\text { (Icr) }\end{array}$ & $\mathrm{Icr}=(\mathrm{Dcr} / \mathrm{Dot}) \times 100$ & $\begin{array}{l}\text { Dcr: Domicílios } \\
\text { atendidos por coleta de } \\
\text { resíduos. } \\
\text { Dot: Domicílios totais }\end{array}$ & $\%$ & $\begin{array}{l}\text { Quantificar o } \\
\text { percentual de } \\
\text { domicílios com } \\
\text { coleta de resíduos } \\
\text { sólidos. }\end{array}$ \\
\hline & $\begin{array}{l}\text { Destinação Final } \\
\text { (Idf) }\end{array}$ & $\begin{array}{l}\text { Idf }=[(\text { Der+Ddc+Ddt+Dqr }) / D o t] \\
x 100\end{array}$ & $\begin{array}{l}\text { Der: Domicílios que } \\
\text { enterram o resíduo; } \\
\text { Ddc: Domicílios que } \\
\text { descartam em curso } \\
\text { d'água; } \\
\text { Ddt: Domicílios que } \\
\text { descartam em terreno } \\
\text { baldio; } \\
\text { Dqr: Domicílios que } \\
\text { queimam os resíduos. }\end{array}$ & $\begin{array}{l}0=100 \\
1-25=75 \\
26-50=50 \\
51-75=25 \\
\text { Acima de } 75 \\
=0\end{array}$ & $\begin{array}{l}\text { Quantificar o } \\
\text { percentual de } \\
\text { domicílios com } \\
\text { destinação final } \\
\text { inadequada dos } \\
\text { resíduos. }\end{array}$ \\
\hline & $\begin{array}{l}\text { Consórcio de } \\
\text { Resíduos Sólidos } \\
\text { (Icp) }\end{array}$ & Critério: Sim - 100; Não - 0 & - & $\begin{array}{l}\text { Sim - } 100 \\
\text { Não - } 0\end{array}$ & $\begin{array}{l}\text { Identificar a } \\
\text { participação em } \\
\text { consórcio de } \\
\text { resíduos sólidos. }\end{array}$ \\
\hline
\end{tabular}

Fonte: Adaptado de Almeida (1999).

O subindicador Consórcio de Resíduos Sólidos (Icp) foi proposto por se tratar de uma solução viável e que tem sido adotada por muitos municípios para a gestão dos resíduos sólidos. O Icp visa identificar a participação dos municípios de pequeno porte nesse tipo de consórcio. A pontuação atribuída segue esse critério de participação, em caso de 'sim' a pontuação é 100 e em caso de 'não' fazer parte de consórcio de resíduos sólidos a pontuação é 0 . 


\section{Indicador de Drenagem Urbana (IDU)}

O Indicador de Drenagem Urbana (IDU) não foi proposto pelo ISA, mas foi incorporado ao cálculo por outros estudos e aplicações em outras localidades. Almeida (1999) foi o primeiro a propor a inclusão do IDU, que foi chamado por ele de 'IDR'. Os estudos que adotaram o IDU propuseram indicadores de segunda ordem variados. Vale salientar que alguns já possuíam base de dados de drenagem da área em estudo, que propôs os subindicadores de Ocorrência de Inundação e Alagamento no Domicílio (lia) e o de Pavimentação das Ruas (Irp).

O IDU proposto para o ISA/MPP é calculado através da equação IDU= lai + Ipv+ Imd + Icv / 4 (Quadro 4) e possui o peso de 0,13 (Tabela 4). O Indicador de Domicílios atingidos por Alagamentos, Inundações e/ou Enchentes (lai), tem como finalidade identificar a ocorrência de alagamento, inundação e/ou enchente e o percentual de domicílios afetados (Quadro 4). O critério de pontuação atribuído ao lai foi distribuído em cinco faixas de resultados quanto ao percentual de domicílios que são atingidos por alagamentos, inundações e/ou enchentes, quando esse percentual for de: i) 0\%, o lai terá pontuação máxima de 100 pontos; ii) 1 25\%, 75 pontos, iii) 26 - 50\%, 50 pontos; iv) 51 - 75\%, 25 pontos; v) e quando esse percentual for acima de 30\%, o lai receberá a pontuação mínima, 0 pontos. Os dados sobre os domicílios atingidos, que compõem o Iai, foram obtidos através de consulta a base de dados do SNIS. Os municípios que não informaram tais dados no SNIS foram consultados diretamente e apenas um ficou sem a informação desse subindicador.

Os demais indicadores de segunda ordem são: Vias pavimentadas (Ipv), que tem como objetivo quantificar o percentual de vias pavimentadas e possui pontuação direta correspondente a esse percentual; Vias com Microdrenagem (Imd), que visa quantificar o percentual de vias pavimentadas com sistema de microdrenagem, a pontuação também corresponde ao valor do percentual; e Cobertura Vegetal (Icv), que visa quantificar o percentual de cobertura vegetal em relação a área total considerada (Quadro 4).

A pontuação atribuída ao Icv considerou estudos que seguem a recomendação de Oke (1973), que considera um índice de $30 \%$ de cobertura vegetal como o indicado para a manutenção do balanço térmico de áreas urbanas, seja um loteamento, um bairro ou um município (LOMBARDO, 1985, citado por ROCHA et al., 2019).

A partir dessa informação, o critério de pontuação atribuído ao Icv foi distribuído em cinco faixas de resultados quanto ao percentual de cobertura vegetal do município, quando esse percentual for de: i) $0 \%$, o Icv terá pontuação mínima de 0 pontos; ii) 1 - 10\%, 25 pontos, iii) 11 - 20\%, 50 pontos; iv) 21 - $30 \%$, 25 pontos; v) e quando o percentual de cobertura vegetal for acima de 30\%, o lcv receberá a pontuação mínima, 0 pontos

O Ipv e o Imd também foram compostos por dados do SNIS, como: extensão total das vias, extensão das vias pavimentadas e extensão das vias com microdrenagem. Nos casos em que os municípios não informaram esses dados pelo SNIS, utilizou-se como alternativa a elaboração do desenho de todas essas vias no Google Earth para calcular a extensão total das vias, extensão das vias pavimentadas e das vias com microdrenagem, que foram observadas através do modo 'Street View'. 
Quadro 4: Método de aplicação do Indicador de Drenagem Urbana (IDU).

\begin{tabular}{|c|c|c|c|c|c|}
\hline $\begin{array}{l}\text { 을 } \\
\text { 를 }\end{array}$ & Indicador & $\begin{array}{l}\text { Cálculo/ } \\
\text { Critério }\end{array}$ & Siglas & Pontuação & Objetivo \\
\hline 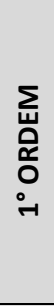 & $\begin{array}{l}\text { Indicador de } \\
\text { Drenagem Urbana } \\
\text { (IDU) }\end{array}$ & $\begin{array}{l}\text { IDU = Iai + Ipv+ } \\
\text { Imd + Icv / } 4\end{array}$ & $\begin{array}{l}\text { Iai: Indicador de domicílios } \\
\text { atingidos por alagamento, } \\
\text { inundação e/ou enchente; } \\
\text { Ipv: Indicador de pavimentação } \\
\text { das vias; } \\
\text { Imd: Indicador de vias com } \\
\text { microdrenagem; Icv: Indicador de } \\
\text { cobertura vegetal. }\end{array}$ & $\begin{array}{l}\text { Média dos } \\
\text { indicadores de } 2^{\circ} \\
\text { ordem }\end{array}$ & $\begin{array}{l}\text { Quantificar a } \\
\text { pontuação } \\
\text { média dos } \\
\text { indicadores de } \\
\text { segunda ordem. }\end{array}$ \\
\hline \multirow{4}{*}{$\begin{array}{l}\sum_{\text {山े }} \\
\text { ั̊ } \\
\text { Oे } \\
\stackrel{N}{N}\end{array}$} & $\begin{array}{l}\text { Domicílios Atingidos } \\
\text { por Alagamento, } \\
\text { Inundação e/ou } \\
\text { Enchente (lai) }\end{array}$ & $\begin{array}{l}\text { lai=(Dai/Dot) } x \\
100\end{array}$ & $\begin{array}{l}\text { Dai: Domicílios atingidos; } \\
\text { Dot: Domicílios totais. }\end{array}$ & $\begin{array}{l}0=100 \\
1-10=75 \\
11-20=50 \\
21-30=25 \\
\text { Acima de } 30=0\end{array}$ & $\begin{array}{l}\text { Quantificar o } \\
\text { percentual de } \\
\text { municípios } \\
\text { atingidos por } \\
\text { alagamento, } \\
\text { inundação e/ou } \\
\text { enchente. }\end{array}$ \\
\hline & $\begin{array}{l}\text { Vias Pavimentadas } \\
\text { (Ipv) }\end{array}$ & $\begin{array}{l}\text { Ipv }=(\text { Etp/Etv }) x \\
100\end{array}$ & $\begin{array}{l}\text { Etp: Extensão total de vias } \\
\text { pavimentadas } \\
\text { Etv:Extensão total de vias. }\end{array}$ & $\%$ & $\begin{array}{l}\text { Quantificar o } \\
\text { percentual de } \\
\text { vias } \\
\text { pavimentadas. }\end{array}$ \\
\hline & $\begin{array}{l}\text { Vias com } \\
\text { Microdrenagem } \\
\text { (Imd) }\end{array}$ & $\begin{array}{l}\text { Imd }=(\text { Emd } / \text { Etp }) \\
x 100\end{array}$ & $\begin{array}{l}\text { Emd:Extensão de vias com } \\
\text { microdrenagem; } \\
\text { Etp:Extensão total de vias } \\
\text { pavimentadas. }\end{array}$ & $\%$ & $\begin{array}{l}\text { Quantificar o } \\
\text { percentual de } \\
\text { vias } \\
\text { pavimentadas } \\
\text { com } \\
\text { microdrenagem }\end{array}$ \\
\hline & $\begin{array}{l}\text { Cobertura Vegetal } \\
\text { (Icv) }\end{array}$ & $\begin{array}{l}I C V=(\text { Acv } / \text { Atc }) x \\
100\end{array}$ & $\begin{array}{l}\text { Acv: Área total de cobertura } \\
\text { vegetal } \\
\text { Atc: Área total considerada. }\end{array}$ & $\begin{array}{l}0=0 \\
1-10=25 \\
11-20=50 \\
21-30=75 \\
\text { Acima de } 30=100\end{array}$ & $\begin{array}{l}\text { Quantificar o } \\
\text { percentual de } \\
\text { cobertura } \\
\text { vegetal. }\end{array}$ \\
\hline
\end{tabular}

Fonte: Adaptado de Almeida (1999).

Em relação aos dados do Icv, foi necessário utilizar o software Quantum Gis (QGIS) para gerar uma imagem raster da área adotada (mancha urbana) de cada municípios em estudo, a partir dessa imagem foram criadas amostras de classes para identificar os componentes da imagem, em um arquivo shapefile, atribuindo valores numéricos ('id'), onde as amostras em polígonos eram classificados da seguinte forma (Figura 1): $1=$ áreas impermeáveis (em vermelho); 2 = cobertura vegetal arbórea e arbustiva (em verde escuro); 3 = cobertura vegetal rasteira (em verde claro); 4 = solo exposto (em amarelo); 5 = curso d'água (em azul).

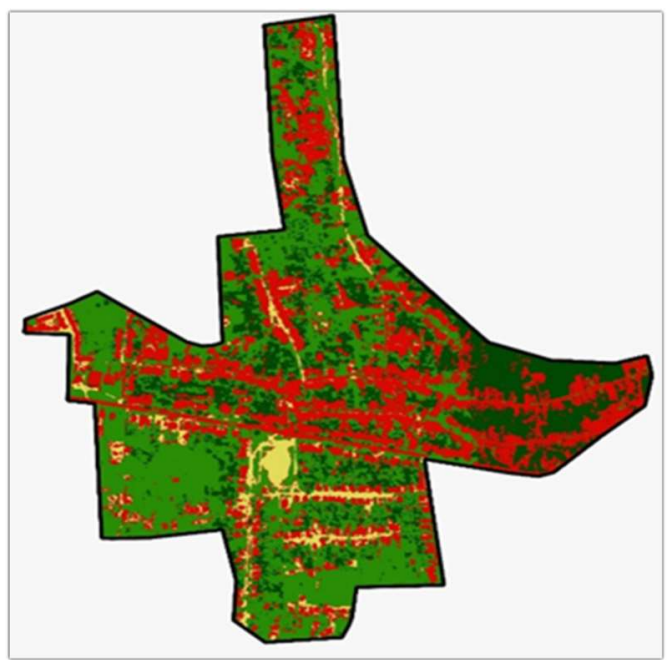

Figura 3: Exemplo do resultado da metodologia aplicada para o Icv em Marcação - PB. 
Utilizou-se o 'plugin Dzetsaka' para classificar as imagens de satélite dos municípios e gerar um produto de sensoriamento remoto com base nos valores numéricos 'id' predefinidos no arquivo shapefile, o qual permitiu o reconhecimento do uso e ocupação do solo das áreas em estudo (Figura 1). A partir das imagens classificadas obtidas por meio desse processo metodológico, tornou-se possível calcular a área total e a ocupada pelos diferentes usos e ocupações do solo através da aplicação do r.report (ferramenta raster), e obter os dados necessários para calcular o lcv.

\section{Indicador de Saúde Pública (ISP)}

O Indicador de Saúde Pública (ISP) foi proposto em substituição ao Indicador de Controle de Vetores (ICV) com o objetivo de abranger outros indicadores de segunda ordem, já que o ICV incluía apenas subindicadores de Dengue, Leptospirose e Esquistossomose, e não permitia identificar outras problemáticas do setor de saneamento que afetam a saúde pública, como outras endemias e epidemias. Também não considerava a relação da mortalidade infantil com a situação dos serviços de saneamento básico e as condições de salubridade ambiental dos municípios e localidades.

O ISP, proposto no ISA/MPP, possui peso de 0,06 (Tabela 4) e o seu método de cálculo é através da seguinte equação: ISP= (Imi + lee+ Ims)/3 (Quadro 5). Os indicadores de segunda ordem são: Indicador de Mortalidade Infantil (Imi); Indicador de Endemias ou Epidemias (lee); e Indicador de Médicos - SUS (Ims).

No caso do Indicador de Mortalidade Infantil (Imi), adotou-se como critério a classificação do Departamento de Informática do Sistema Único de Saúde (DATASUS) que estabelece que as taxas de mortalidade infantil com 50 ou mais mortos para cada 1 mil nascidos vivos são consideradas altas, por essa razão foi atribuído ao primeiro valor, com a pior pontuação, zero pontos.

Para a formulação do Indicador de Endemias ou Epidemias (lee), foram considerados os dados do IBGE referentes a ocorrência de doenças associadas ao saneamento básico nos últimos 12 meses do ano de 2017, que são os dados mais recentes. Foram consideradas sete doenças para compor esse subindicador, são elas: Diarreia (Dia), Leptospirose (Lep), Verminose (Ver), Dengue (Den), Zika (Zik), Chikungunya (Chi) e Hepatite (Hep). De acordo com critério de ocorrência foram atribuídos o valor de 1, quando houve endemias e epidemias da doença, ou de 0 , quando não houve registros.

O lee corresponde ao resultado da soma dos valores atribuídos a ocorrência de endemias e epidemias por cada doença considerada, dividido pelo número total de doenças (sete). Quanto mais ocorrência de doenças o município apresentar, mais o lee se aproximará de 1, que corresponde ao primeiro valor da pontuação. Ou seja: quando o lee for 1 , sua pontuação será 0 ; quando estiver entre $0,99-0,80$, será 25 pontos; quando estiver entre $0,79-0,60$, será 50 pontos; quando o lee estiver entre 0,59-0,40, a pontuação será 75 pontos; e quando estiver entre $0,39-0,00$, a pontuação do lee será igual a 100 pontos (Quadro 5).

O último indicador proposto para compor o Indicador de Saúde Pública (ISP) se refere ao percentual de médicos que atendem pelo SUS em relação a população total do município, obtido através do Indicador de Médicos - SUS (Ims). O Ims é composto pelo dado disponibilizado pelo Caderno de Informações de Saúde 
de cada município sobre o total de médicos que atendem pelo SUS, a fonte desse dado foi o Cadastro Nacional de Estabelecimentos de Saúde - CNES (base de dados nacional consultada em 2010).

Quadro 5: Método de aplicação do Indicador de Saúde Pública (ISP).

\begin{tabular}{|c|c|c|c|c|c|}
\hline$F$ & Indicador & Cálculo/Critério & Siglas & Pontuação & Objetivo \\
\hline $\begin{array}{l}\sum_{\text {ü }} \\
0 \\
\text { ô } \\
0 \\
0\end{array}$ & $\begin{array}{l}\text { Indicador de Saúde } \\
\text { Pública (ISP) }\end{array}$ & $I S P=(I m i+l e e+I m s) / 3$ & $\begin{array}{l}\text { Imi: Indicador de } \\
\text { mortalidade infantil; } \\
\text { lee: Indicador de } \\
\text { endemias/epidemias } \\
\text { Ims: Indicador de } \\
\text { médicos. }\end{array}$ & $\begin{array}{l}\text { Média dos } \\
\text { indicadores de } 2^{\circ} \\
\text { ordem }\end{array}$ & $\begin{array}{l}\text { Quantificar a } \\
\text { pontuação } \\
\text { média dos } \\
\text { indicadores de } \\
\text { segunda ordem. }\end{array}$ \\
\hline \multirow{3}{*}{ 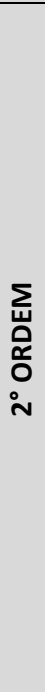 } & $\begin{array}{l}\text { Indicador de } \\
\text { Mortalidade Infantil } \\
\text { (Imi) }\end{array}$ & Dados do IBGE/2010 & - & $\begin{array}{l}\text { Acima de } 50=0 \\
40-49=25 ; \\
30-39=50 ; \\
20-29=75 \\
\text { Até } 20=100\end{array}$ & $\begin{array}{l}\text { Identificar o } \\
\text { percentual de } \\
\text { mortalidade } \\
\text { infantil do } \\
\text { município. }\end{array}$ \\
\hline & $\begin{array}{l}\text { Indicador de } \\
\text { Endemias ou } \\
\text { Epidemias (lee) }\end{array}$ & $\begin{array}{l}\text { lee }=(\text { Dia }+ \text { Lep }+ \text { Ver }+ \\
\text { Den + Zik + Chi + Hep) } / 7 \\
\text { Ocorrência (critério): } \\
\text { Não }=0 \\
\text { Sim }=1\end{array}$ & $\begin{array}{l}\text { Dia: Diarreia } \\
\text { Lep: Leptospirose } \\
\text { Ver: Verminose } \\
\text { Den: Dengue } \\
\text { Zik:Zika } \\
\text { Chi: Chikungunya } \\
\text { Hep: Hepatite } \\
\end{array}$ & $\begin{array}{l}\text { lee } \\
\text { Acima de } 1,0=0 \\
0,99-0,80=25 \\
0,79-0,60=50 \\
0,59-0,40=75 \\
0,39-0,00=100\end{array}$ & $\begin{array}{l}\text { Quantificar o } \\
\text { indicador de } \\
\text { acordo com a } \\
\text { ocorrência de } \\
\text { endemias e } \\
\text { epidemias no } \\
\text { município. } \\
\end{array}$ \\
\hline & $\begin{array}{l}\text { Indicador de Médicos } \\
\text { - SUS (Ims) }\end{array}$ & $\begin{array}{l}\text { Ims = (Tmd/Tpo) x } 1000 \\
\text { Quantidade de Médicos } \\
\text { do SUS por mil } \\
\text { habitantes. }\end{array}$ & $\begin{array}{l}\text { Tmd: Total de } \\
\text { médicos (SUS) } \\
\text { Tpo: Total da } \\
\text { população do } \\
\text { município. }\end{array}$ & $\begin{array}{l}0 \text { a } 0,25=0 \\
0,26 \text { a } 0,50=25 \\
0,56 \text { a } 0,75=50 \\
0,76 \text { a } 0,99=75 \\
\text { Acima de } 1,0= \\
100\end{array}$ & $\begin{array}{l}\text { Quantificar o } \\
\text { percentual de } \\
\text { médicos do SUS } \\
\text { em relação a } \\
\text { pop. total do } \\
\text { município. } \\
\end{array}$ \\
\hline
\end{tabular}

Fonte: Adaptado de Almeida (1999).

\section{Índice de Desenvolvimento Humano (IDH)}

A adoção do Índice de Desenvolvimento Humano (IDH) foi proposta em substituição ao Indicador Socioeconômico (ISE), que tinha como indicadores de segunda ordem o Indicador de Saúde Pública (Isp), Indicador de Renda (Irf) e Indicador de Educação (led). O Indicador de Saúde Pública, que no ISE era um subindicador, está sendo considerado separadamente como um Indicador de primeira ordem do ISA/MPP. Os Indicadores de Renda e Educação permanecem como indicadores de segunda ordem do IDH, pois já compõem o Índice de Desenvolvimento Humano adotado, além do Indicador de Longevidade. O IDH, como indicador de primeira ordem do ISA/MPP, é obtido através da fórmula IDH= $(\mathbf{I l} \mathbf{d}+\mathbf{I r f}+\mathbf{l e d}) / \mathbf{3}$ e possui o peso de $\mathbf{0 , 0 6}$ (Tabela 4).

Foram considerados os Índices de Desenvolvimento Humano dos Municípios (IDHM) já existentes, publicados pelo Atlas Brasil (2013) para compor o IDH. A pontuação será atribuída de acordo com a classificação do IDH: entre 0,000 - 0,499 o IDH é considerado muito baixo, por isso sua pontuação será igual a 0; entre 0,500-0,599 o IDH é baixo e receberá 25 pontos; entre 0,600-0,699 é considerado um IDH médio e receberá 50 pontos; entre $0,700-0,799$ é um IDH alto e receberá 75 pontos; e entre $0,80-1,00$ será considerado um IDH muito alto, o que corresponde a pontuação máxima, igual a 100 pontos. Dessa forma, foram utilizados os últimos dados de IDHM publicados, que são do ano de 2010, para calcular a pontuação do Índice de Desenvolvimento Humano (IDH), que compõe o ISA/MPP, seguindo os critérios de pontuação apresentados. 
Quadro 6: Método de aplicação do Índice de Desenvolvimento Humano (IDH).

\begin{tabular}{|c|c|c|c|c|c|}
\hline F & Indicador & Cálculo/Critério & Siglas & Pontuação & Objetivo \\
\hline $\begin{array}{l}\sum_{\text {ü }} \\
0 \\
\text { ố } \\
0 \\
\circ\end{array}$ & $\begin{array}{l}\text { Índice de } \\
\text { Desenvolvimento } \\
\text { Humano do } \\
\text { Município (IDH) }\end{array}$ & $\begin{array}{l}\text { IDH }=(I I d+I r f+l e d) \\
/ 3\end{array}$ & $\begin{array}{l}\text { Ild: Indicador } \\
\text { municipal de } \\
\text { longevidade; } \\
\text { Irf: Indicador } \\
\text { municipal de } \\
\text { renda familiar; } \\
\text { led: Indicador } \\
\text { municipal de } \\
\text { educação. }\end{array}$ & $\begin{array}{l}\text { Média dos } \\
\text { indicadores de } 2^{\circ} \\
\text { ordem }\end{array}$ & $\begin{array}{l}\text { Quantificar a } \\
\text { pontuação média dos } \\
\text { indicadores de } \\
\text { segunda ordem. }\end{array}$ \\
\hline \multirow{3}{*}{ 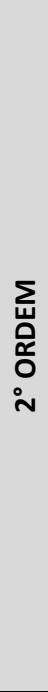 } & $\begin{array}{l}\text { IDHM - } \\
\text { Longevidade (IId) }\end{array}$ & $\begin{array}{l}\text { Dados Atlas Brasil } \\
2013\end{array}$ & 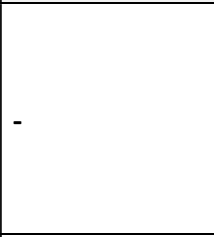 & $\begin{array}{l}0,000-0,499=0 \\
0,500-0,599=25 ; \\
0,600-0,699=50 ; \\
0,700-0,799=75 ; \\
0,800-1,000= \\
100 .\end{array}$ & $\begin{array}{l}\text { Quantificar o } \\
\text { subindicador de } \\
\text { longevidade de } \\
\text { acordo com os dados } \\
\text { do IDHM. }\end{array}$ \\
\hline & IDHM - Renda (Irf) & $\begin{array}{l}\text { Dados Atlas Brasil } \\
2013\end{array}$ & - & $\begin{array}{l}0,000-0,499=0 \\
0,500-0,599=25 ; \\
0,600-0,699=50 ; \\
0,700-0,799=75 ; \\
0,800-1,000= \\
100 .\end{array}$ & $\begin{array}{l}\text { Quantificar o } \\
\text { subindicador de renda } \\
\text { de acordo com os } \\
\text { dados do IDHM. }\end{array}$ \\
\hline & $\begin{array}{l}\text { IDHM- Educação } \\
\text { (led) }\end{array}$ & $\begin{array}{l}\text { Dados Atlas Brasil } \\
2013\end{array}$ & - & $\begin{array}{l}0,000-0,499=0 \\
0,500-0,599=25 ; \\
0,600-0,699=50 ; \\
0,700-0,799=75 ; \\
0,800-1,000= \\
100 .\end{array}$ & $\begin{array}{l}\text { Quantificar o } \\
\text { subindicador de } \\
\text { educação de acordo } \\
\text { com os dados do } \\
\text { IDHM. }\end{array}$ \\
\hline
\end{tabular}

Fonte: Adaptado de Almeida (1999).

\section{Aplicação do ISA/MPP}

O teste de aplicabilidade do ISA/MPP permitiu observar que os indicadores de primeira e segunda ordem apresentam viabilidade para serem aplicados aos municípios de pequeno porte, como é o caso de Cuité de Mamanguape e Marcação, e, também, aos municípios de grande porte, como é o caso de João Pessoa (Tabela 5).

Tabela 5: Resultados gerais da aplicação do ISA/MPP nos municípios escolhidos.

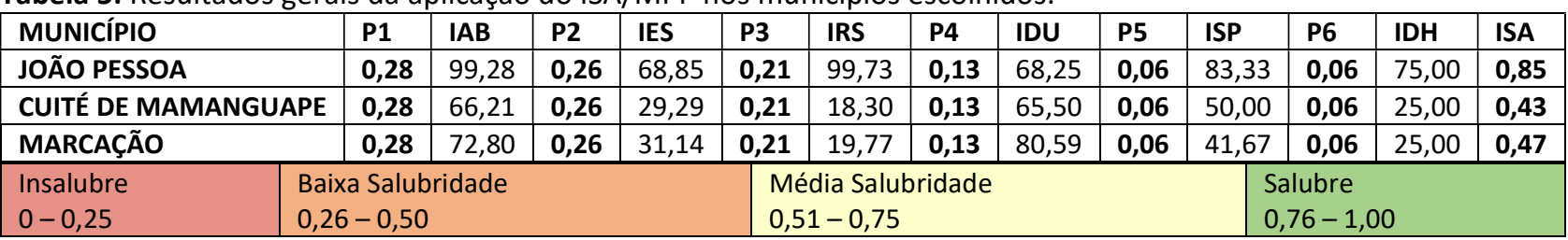

P1: Peso 1; IAB: Indicador de Abastecimento de Água; P2: Peso 2; IES: Indicador de Esgotamento Sanitário; P3: Peso 3; IRS: Indicador de Resíduos Sólidos; P4: Peso 4; IDU: Indicador de Drenagem Urbana; P5: Peso 5; ISP: Indicador de Saúde Pública; P6: Peso 6; IDH: Índice de Desenvolvimento Humano; ISA: Indicador de Salubridade Ambiental.

Os resultados do ISA/MPP apresentam diferenças quanto a salubridade ambiental dos municípios de pequeno porte e do município de grande porte. De acordo com os resultados obtidos, Cuité de Mamanguape e Marcação são classificados como municípios de baixa salubridade, pois apresentaram ISA de 0,43 e 0,47, respectivamente, já João Pessoa é classificado como salubre, pois apresenta ISA de 0,85 (Tabela 5).

\section{CONCLUSÕES}

Antes de propor o ISA/MPP houve a tentativa de aplicar o ISA CONESAN aos municípios de pequeno 
porte, no entanto, o ISA apresentou-se como inviável por incluir dados de difícil acesso ou que avaliam aspectos que não condizem com a realidade desses municípios. Com as adaptações propostas, o modelo ISA/MPP mostrou-se viável tanto ao contexto dos municípios de pequeno porte como ao de municípios de grande porte.

Além disso, o ISA/MPP conseguiu atender a necessidade de incluir dados acessíveis e indicadores que consideram peculiaridades dos serviços de saneamento dos municípios de pequeno porte. Algumas das dificuldades encontradas durante o processo de revisão da literatura para compor o ISA/MPP foi referente a metodologia para a atribuição dos pesos e a definição dos indicadores de segunda ordem. Mesmo com essas dificuldades, as soluções propostas apresentaram um retorno satisfatório. Vale ressaltar a necessidade de revisar os indicadores de segunda ordem propostos e critérios de pontuação no processo de adaptação de um modelo a partir do ISA CONESAN, pois se um indicador for proposto de forma inadequada pode causar distorções nos resultados dos indicadores de primeira ordem e no resultado geral do ISA proposto.

\section{REFERÊNCIAS}

ALMEIDA, M. A. P. D.. Indicadores de Salubridade Ambiental em FavelasUrbanizadas: o Caso de Favelas em Áreas de Proteção Ambiental. Tese (Doutorado em Engenharia Civil) - Universidade de São Paulo, São Paulo, 1999.

APIAÍ. Plano Municipal de Saneamento Básico. Programa de Fortalecimento dos Instrumentos de Planejamento do Setor de Saneamento. Apiaí: Diário Oficial, 2010.

CABRAL, A. C.. Indicador de Salubridade Ambiental relacionado ao consumo de energia e água em municípios lindeiros e não lindeiros ao Lago de Itaipu da Bacia Hidrográfica do Paraná III. Dissertação (Mestrado em Eng. de Energia e Agricultura) - Universidade Estadual do Oeste do Paraná, Cascavel, 2015.

CARVALHO, P. G. M.. Mensurando a Sustentabilidade. In: MAT, P.. Economia do Meio Ambiente. 2 ed. Rio de Janeiro: TJ, 2010. p.99-132.

COSTA, R. V. F.. Desenvolvimento do Índice de Salubridade Ambiental (ISA) para comunidades rurais e sua aplicação e análise nas comunidades de Ouro Branco - MG. Dissertação (Mestrado em Engenharia Ambiental) - Universidade Federal de Ouro Preto, Ouro Preto, 2010.

CUNHA, T. B.. Análise integrada de salubridade ambiental e condições de moradia: aplicação no município de Itaguaçu da Bahia. Dissertação (Mestrado em Engenharia Urbana e Ambiental) - Universidade Federal da Paraíba, João Pessoa, 2012.

IBGE. Instituto Brasileiro de Geografia e Estatística. Base Suplemento MUNIC 2017 Aspectos gerais de gestão da política de saneamento básico. Rio de Janeiro: IBGE, 2017.

IBGE. Instituto Brasileiro de Geografia e Estatística. Perfil dos municípios brasileiros: Saneamento básico: Aspectos gerais de gestão da política de saneamento básico. Rio de Janeiro: IBGE, 2018.

MINISTÉRIO DAS CIDADES. Plano Nacional de Saneamento Básico - PLANSAB. Brasília, 2013.

OLÍMPIA. Plano de Saneamento Ambiental de Olímpia. Relatório Final. Olímipia: Prefeitura, 2010.

ROCHA, M. F.; NUCCl, J. C.. Cobertura vegetal na região central das capitais brasileiras. GEOgraphia, Niterói, v.21, n.45, 2019.

SILVA, N. V. S.. As condições de salubridade ambiental das comunidades periurbanas da Bacia do Baixo Gramame: Diagnóstico e Proposição de Benefícios. Dissertação (Mestrado em Engenharia Urbana) - Universidade Federal da Paraíba, João Pessoa, 2006.

SOUZA, M. C. C. A.. Análise das condições de Salubridade Ambiental intra-urbana em Santa Rita - PB. Dissertação (Mestrado em Geografia) - Universidade Federal da Paraíba, João Pessoa, 2010.

TEIXEIRA, D. A.. Construção e Determinação do Indicador de Salubridade Ambiental (ISA/OP) para Áreas Urbanas do Município de Ouro Preto, MG. Dissertação (Mestrado em Engenharia Ambiental) - Universidade Federal de Ouro Preto, Ouro Preto, 2017.

TEIXEIRA, D. A.; PRADO FILHO, J. F.; SANTIAGO, A. F. Indicador de salubridade ambiental: variações da formulação e usos do indicador no Brasil. Revista Eng Sanit Ambient, v.23, n.3, p.543-556, 2018. DOI: http://doi.org/10.1590/S1413-41522018170866

ZANCUL, J. D. S.. Direitos Humanos à Água e ao Saneamento e a Política de Saneamento Básico no Brasil. Cad. IberoAmer. Dir. Sanit., Brasília, v.4, n.2, p.23-46, 2015.

A CBPC - Companhia Brasileira de Produção Científica (CNPJ: 11.221.422/0001-03) detém os direitos materiais desta publicação. Os direitos referem-se à publicação do trabalho em qualquer parte do mundo, incluindo os direitos às renovaç̃ões, expansões e disseminações da contribuiç̃o, bem como outros direitos subsidiários. Todos os trabalhos publicados eletronicamente poderão posteriormente ser publicados em coletâneas impressas sob coordenação da Sustenere Publishing, da Companhia Brasileira de Produção Científica e seus parceiros autorizados. Os (as) autores (as) preservam os direitos autorais, mas não têm permissão para a publicação da contribuição em outro meio, impresso ou digital, em português ou em tradução. 